LA WRE NCE LWEAMCAE NATIONAL LABOAATOAY

Investigation of $\mathrm{HCCl}$

Combustion of Diethyl Ether and Ethanol Mixtures

Using Carbon 14 Tracing and Numerical Simulations

J. H. Mack, D.L. Flowers, B. A. Buchholz, R. W. Dibble

August 1, 2004

Presented at the $30^{\text {th }}$ International Symposium on Combustion

Chicago, Illinois

July 25-30, 2004 
This document was prepared as an account of work sponsored by an agency of the United States Government. Neither the United States Government nor the University of California nor any of their employees, makes any warranty, express or implied, or assumes any legal liability or responsibility for the accuracy, completeness, or usefulness of any information, apparatus, product, or process disclosed, or represents that its use would not infringe privately owned rights. Reference herein to any specific commercial product, process, or service by trade name, trademark, manufacturer, or otherwise, does not necessarily constitute or imply its endorsement, recommendation, or favoring by the United States Government or the University of California. The views and opinions of authors expressed herein do not necessarily state or reflect those of the United States Government or the University of California, and shall not be used for advertising or product endorsement purposes. 


\title{
Investigation of HCCI Combustion of Diethyl Ether and Ethanol Mixtures Using Carbon 14 Tracing and Numerical Simulations
}

\author{
J.H. Mack ${ }^{a^{*}}$, D.L. Flowers ${ }^{b}$, B.A. Buchholz ${ }^{c}$, R.W. Dibble ${ }^{a}$ \\ ${ }^{a}$ Combustion Analysis Laboratory, University of California Berkeley, Berkeley, CA 94720 USA \\ ${ }^{b}$ Lawrence Livermore National Laboratory, Livermore, CA 94551 USA \\ ${ }^{c}$ Center for Accelerator Mass Spectrometry, Lawrence Livermore National Laboratory, Livermore, CA 94551 USA \\ "Corresponding Author: Univ. of California, Hesse Hall 50-B, Berkeley, CA 94720 USA \\ Fax: 1-510-642-1850, Email: hmack@me.berkeley.edu
}

\begin{abstract}
Despite the rapid combustion typically experienced in Homogeneous Charge Compression Ignition (HCCI), components in fuel mixtures do not ignite in unison or burn equally. In our experiments and modeling of blends of diethyl ether (DEE) and ethanol (EtOH), the DEE led combustion and proceeded further toward completion, as indicated by ${ }^{14} \mathrm{C}$ isotope tracing. A numerical model of HCCI combustion of DEE and EtOH mixtures supports the isotopic findings. Although both approaches lacked information on incompletely combusted intermediates plentiful in HCCI emissions, the numerical model and ${ }^{14} \mathrm{C}$ tracing data agreed within the limitations of the single zone model. Despite the fact that DEE is more reactive than EtOH in HCCI engines, they are sufficiently similar that we did not observe a large elongation of energy release or significant reduction in inlet temperature required for light-off, both desired effects for the combustion event. This finding suggests that, in general, HCCI combustion of fuel blends may have preferential combustion of some of the blend components.
\end{abstract}

Keywords: HCCI, HCCI modeling, mass spectrometry, biofuel, combustion efficiency 


\section{Introduction}

\subsection{Homogeneous Charge Compression Ignition}

The Homogeneous Charge Compression Ignition (HCCI) engine has received renewed interest in recent years. In the past decade, several hundred papers have been published, largely in the literature of the Society of Automotive Engineers. A recent text reviews much of this literature [1]. HCCI engines have features of both spark ignited (SI) engines and Diesel engines. Like SI engines, HCCI engines are generally premixed and lean at $<0.5$, thus they produce very low nitrous oxides (NOx) and particulate emissions (PM). Yet, HCCI engines typically have high compression ratios and high efficiencies similar to that found in Diesel engines. In an SI engine, the combustion event is initiated by a spark and timing of the spark is routinely adjusted. Similarly, the combustion event in a Diesel engine is initiated by injection of the Diesel fuel. The injection time

and duration is variable. However, the HCCI engine does not have a spark plug or direct fuel injection; the combustion event occurs when the cylinder contents are hot enough (approximately $1200 \mathrm{~K}$ ) for a long enough time (around 3 milliseconds). In this paper, the combustion event (CA50) is defined as time when $50 \%$ of the cumulative heat release has occurred [2].

However, a major problem with HCCI is that the combustion event happens rapidly resulting in a pressure rise rate that can exceed $10 \mathrm{bar} / \mathrm{ms}$, which exceeds the material limits of the rings on a piston engine [3]. One strategy to spread out the combustion event is to use a blend of two fuels that have different autoignition characteristics (i.e. different autoignition times). The goal is that one fuel would burn earlier than another and thus spread out the HCCI combustion duration. Furthermore, addition of fuel with a low autoignition temperature lowers the intake temperature required for HCCI operation. Intake temperature is typically a slowly responding parameter, with lags associated with heating a flowing gas. Small changes in temperature can dramatically affect CA50, so overshooting a target temperature can push the combustion into an unstable regime [4-6]. By using DEE in the two-component fuel set-up, the required light-off temperature is easier to obtain. Examples of this strategy include using dimethyl ether (easy to autoignite) mixed with methane (difficult to autoignite) [7], naptha with methane [8], and octane with n-heptane [9].

In this paper, we explore the HCCI combustion of a blend of ethanol (EtOH) with the ether of ethanol, diethyl ether (DEE, sometimes written as EtOEt). Both can be derived from biological feed stocks. DEE autoignites more readily than ethanol. Thus, the goal was to find a blend that spreads the overall combustion 
event and reduces the autoignition temperature relative to EtOH. We anticipate that DEE will autoignite first followed by autoignition of ethanol. We observed this sequence of events by using the natural carbon-14 $\left({ }^{14} \mathrm{C}\right)$ level in bio-derived EtOH as a tracer.

The single cylinder engine used in these experiments is a Caterpillar 3401 (see Table I). The engine was maintained at constant speed of $\sim 1800 \mathrm{RPM}$ by an induction motor/generator. Intake temperatures were changed using an electrical heater located 1 meter upstream of the engine. Liquid fuel injectors, mounted $\sim 0.75$ meter upstream, controlled the equivalence ratio.

\subsection{Carbon 14}

Chemical pathways of combustion can be identified through tracing and measurement of unusual isotopes. Radioisotopes are specific and distinctive because they are extremely rare in natural materials. A radioisotope-labeled compound has a very high abundance-to-background ratio, but poor detection efficiency may obscure this property. Using a long-lived radioisotope (e.g., ${ }^{14} \mathrm{C}$ half life $=5730$ years) can ameliorate issues associated with radioactivity if the detector measures mass rather than radioactive decays. Accelerator mass spectrometry (AMS), an isotope-ratio measurement method developed in the late 1970s for radiocarbon dating is ideally suited to measure variations from the natural level of ${ }^{14} \mathrm{C} / \mathrm{C}=10 \mathrm{E}-12$ against a petroleum background ${ }^{14} \mathrm{C} / \mathrm{C}<10 \mathrm{E}-15$ [10]. Accordingly, components of bio-derived fuels contain elevated ${ }^{14} \mathrm{C}$ as compared to fossil fuels. This isotopic elevation is sufficient to trace the fate of bio-derived fuel components (ethanol) in emission products without the use of radioactive materials.

The methods described below for tracing fuel component carbon in the emissions can be applied to any combustion system. Any molecule containing carbon can be labeled with ${ }^{14} \mathrm{C}$. Although only recently applied to studies of engine combustion processes [11-15], the techniques for measuring the ${ }^{14} \mathrm{C}$ concentrations of $\mathrm{PM}$ and $\mathrm{CO}_{2}$ by AMS are straightforward and routine.

\section{Experimental Procedure}

The equivalence ratio was maintained at $=0.3$ or 0.4 throughout the course of the experiment. The intake boost pressure was at a constant $\mathrm{P}=1.7$ bar. Grain ethanol $(\mathrm{EtOH})$ served as the tracer (bio-derived, contains ${ }^{14} \mathrm{C}$ ) fuel while diethyl ether (DEE) was the petroleum-derived fuel $\left({ }^{14} \mathrm{C}\right.$ free). The isotopic level of the lubrication oil and DEE was at instrument background $\left({ }^{14} \mathrm{C} / \mathrm{C}\right.$ ratios $\left.<10 \mathrm{E}-15\right)$. Since the ethanol is bio-derived, 
it is uniformly labeled; each carbon atom in the ethanol molecule is equally labeled with ${ }^{14} \mathrm{C}$. The properties of these two fuels are listed below in Table II. DEE in EtOH blends containing 12.5 and 25\% DEE were used (defined on a volume percent basis; e.g. $250 \mathrm{~mL}$ DEE for every $750 \mathrm{~mL} \mathrm{EtOH}$ at $25 \%$ ).

Exhaust gas samples were collected at varied combustion timings for each fuel mixture. CA50 was controlled by the intake temperature. Exhaust gas was routed from the exhaust manifold through a particulate filter and into Tedlar bags. No particulate matter was deposited on the filter. Figure 1 shows the experimental set-up.

The gas sample bags were maintained at temperatures between 290-300 K and processed within several days of collection. Bags were equilibrated with an evacuated $\sim 60 \mathrm{~mL}$ volume to obtain AMS samples containing 0.2-1.1 mg C from separated $\mathrm{CO}_{2}$. All gas molecules except $\mathrm{N}_{2}$ and $\mathrm{CO}$ were initially condensed with a liquid nitrogen (LN) cold trap. This first cold trap was then switched to dry ice-isopropanol so water, sulfur dioxide, and unburned fuel were retained and second cold trap with LN was placed in series to condense $\mathrm{CO}_{2}$. A valve between the traps was closed and non-condensable gases were removed. The $\mathrm{CO}_{2}$ was then cryogenically transferred to a quartz sample tube which was sealed with a $\mathrm{H}_{2} / \mathrm{O}_{2}$ torch. Each purified $\mathrm{CO}_{2}$ sample was then transferred to our graphitization rig where it passed through another dry ice-isopropanol cold trap and was condensed again with LN. Carbon mass was determined from $\mathrm{CO}_{2}$ pressure in a small fixed volume before transfer to an individual reactor and reduction to graphite in the presence of iron catalyst [16]. All graphite targets were measured at the Center for AMS at LLNL [17]. A general description of how AMS works is available in the literature [10].

AMS is an isotope ratio mass spectrometry technique where ${ }^{14} \mathrm{C} / \mathrm{C}$ ratios of the unknowns are normalized to measurements of 4-6 identically prepared standards of known isotope concentration. The isotope ratio of the sample, $R_{s}$, is calculated from the measured isotope ratios of the sample, $R_{s(m e a s)}$, the average of the measured standards, $R_{\text {stand(meas) }}$, and the known isotope ratio of the standard, $R_{\text {stand }}$, shown in Eq.1.

$$
R_{s}=\frac{R_{s(\text { meas })}}{R_{\text {stand }(\text { meas })}} R_{\text {stand }}
$$

Only the ethanol contains a significant ${ }^{14} \mathrm{C}$ signal in this system. Backgrounds associated with sample prep are known and the contribution of intake air to the exhaust $\mathrm{CO}_{2}$ is subtracted. Expanding the ${ }^{14} \mathrm{C} / \mathrm{C}$ ratio to show the remaining terms for each sample produces a simple expression where $C$ and $R$ denote carbon mass and isotope ratio and the subscripts ${ }_{E}$ and ${ }_{D}$ denote ethanol and DEE, respectively (Eq.2). 


$$
R_{S}=\frac{{ }^{14} C_{E}}{C_{E}+C_{D}}=\frac{C_{E}\left(R_{E}\right)}{C_{E}+C_{D}}
$$

The denominator of Eq.2 is an expression for the total carbon mass of the sample. By manipulating Eq.2 we solve for the fraction of ethanol-derived carbon $F_{E}$ in the sample.

$$
F_{E}=\frac{C_{E}}{C_{E}+C_{D}}=\frac{R_{S}}{R_{E}}
$$

\section{Numerical Model}

Simulations of HCCI combustion of the diethyl-ether-in-ethanol blend have been conducted using a "single-zone" numerical model of the engine. This kind of model treats the combustion chamber as a uniform reactor with uniform temperature, pressure, and composition throughout. Conservation of energy and chemical kinetic relations based on a gas-phase detailed kinetic mechanism for diethyl-ether and ethanol combustion are solved to determine temperature and species histories for the cycle.

The chemical mechanism contains an extension of that for dimethyl ether [18] with diethyl ether chemistry provided by Curran [19] and a mechanism of EtOH [20]. The combined mechanism contains 112 species and 484 reactions.

The reactor volume changes based on slider-crank relations that determine the motion of the piston in the engine cylinder. The simulation handles only the closed part of the cycle; intake and exhaust processes are not considered. The single-zone model is a highly idealized representation of the actual processes occurring in the combustion chamber. Models exist, e.g. KIVA, that that have thousands of zones and thus capture in more detail the three-dimensional processes occurring in the combustion chamber [1,21-23], such as crevice and boundary layer effects. Still, single-zone models can give insight into the processes occurring in the combustion chamber, especially processes that occur in the hottest central core gasses of the combustion chamber away from the crevice and boundary layers. Heat transfer [24-27] and trapped residuals were also included in the model.

Simulations were conducted using the geometric and operating parameters for the engine specified in Table I. 


\section{Results and Discussion}

By selectively labeling fuel components, the tendency of neighboring atoms to influence the sites of molecular cleavage during combustion can be interrogated. The deposition of the tracer into different emission products depends upon the molecular fragments formed during combustion. This type of data can help combustion modelers construct and refine chemical-kinetic combustion mechanisms. We know, for example, that mixtures of DME and methane do not light off simultaneously; DME ignites first and in some cases can completely combust without igniting the methane [23].

When a fuel completely burns in Diesel or SI engines, the isotopic signature of the exhaust $\mathrm{CO}_{2}$ mirrors that of the fuel, with small contributions from lubrication oil and intake air [11-15]. As fuel approaches the flame front, it is conceivable that some fuel components react before others. However, this temporary segregation occurs on a dimension that is a fraction of the flame thickness and produces an imbalance in fuel component ratios in a thin zone that is small compared to the combustion chamber. This transient thin zone exists so long as combustion is occurring. When examining the exhaust for segregation in combustion of fuel species, diffusion over these small zones has long since obliterated any small zones that contained gradients in isotopic species that may have been created by the flame. However, in HCCI combustion, the entire chamber burns nearly in unison. We expect that DEE will autoignite sooner than EtOH because the autoignition temperature of DEE is lower than the autoignition temperature of $\mathrm{EtOH}$.

If combustion proceeds to completion, all of the fuel will be converted to $\mathrm{CO}_{2}$ and the fact that DEE oxidized earlier than EtOH will be obscured. However, when combustion is less than $100 \%$ complete, it is likely that DEE is more completely oxidized than EtOH.

In this work we examined the two component fuel system (DEE in EtOH) and used conventional gas analysis and isotope tracing to examine extent of reaction of each species. The ${ }^{14} \mathrm{C}$ content of the EtOH provides the tracer for determining the fate of the ethanol-derived carbon in the engine emissions. In HCCI, the combustion efficiency of separate fuel components can be monitored by measuring changing isotope levels of the $\mathrm{CO}_{2}$ found in the exhaust.

Plotted in Fig. 2 is zeta $\left(=\left(\mathrm{F}_{\mathrm{E}}\right)_{\mathrm{CO} 2} /\left(\mathrm{F}_{\mathrm{E}}\right)_{\mathrm{FUEL}}\right)$, the mass fraction of ethanol-derived carbon in $\mathrm{CO}_{2}$, compared to mass fraction of ethanol-derived carbon in the fuel. For _ $<1$, DEE burns to $\mathrm{CO}_{2}$ more so than EtOH and thus the exhaust $\mathrm{CO}_{2}$ has a lower fraction of ${ }^{14} \mathrm{C}$ relative to the ${ }^{14} \mathrm{C}$ in the fuel. In all cases in Fig. 2 , we see that DEE is being oxidized to $\mathrm{CO}_{2}$ more than $\mathrm{EtOH}$. Zeta falls further from one as the CA50 occurs later 
in the cycle. Late in the cycle, the volume is expanding causing the temperature to plummet downward and thus freezing the reaction before completion. In this frozen mode, we can easily see that DEE oxidizes to $\mathrm{CO}_{2}$ more readily than EtOH. Even though, oxidation of both DEE and EtOH is impeded as the temperature is dropping, the EtOH oxidation is more impeded.

Gas analyzer data from $25 \% \mathrm{DEE}$ in $\mathrm{EtOH}$ at $=0.4$ are displayed in Fig. 3. The lines are visual aids and not intended as fits. Hydrocarbon ( $\mathrm{HC})$ and $\mathrm{CO}$ concentrations are displayed in ppm while $\mathrm{CO}_{2}$ is displayed in percent. It is clear that later ignition yields less complete combustion. The dramatic drop in $\mathrm{CO}_{2}$ level was also observed in the drop of AMS sample size. The $\mathrm{CO}$ and $\mathrm{HC}$ increase while $\mathrm{CO}_{2}$ drops. However, the drop in $\mathrm{CO}_{2}$ does not lead to a quantitative increase in $\mathrm{CO}$ and $\mathrm{HC}$ since the $\mathrm{HC}$ measure is based on flame ionization detector (FID) which is known to poorly detect oxygenated species. Acetaldehyde is just one example of many oxygenated intermediate species that may be frozen in the expanding mixture. We expect the HC to be a lower limit to what is actually there. So long as there are hydrocarbons in the mixture, the $[\mathrm{OH}]$ remains low since $\mathrm{OH}$ rapidly reacts with the hydrocarbons. Low $[\mathrm{OH}]$ impedes the oxidation of $\mathrm{CO}$ to $\mathrm{CO}_{2}$ via the following reaction.

$$
\begin{gathered}
\mathrm{CO}+\mathrm{OH} \quad \mathrm{CO}_{2}+\mathrm{H} \\
E_{\text {act }} \square 0
\end{gathered}
$$

Hence, the build up of $\mathrm{CO}$ with late CA50. Furthermore, late in the cycle, the temperature is decreasing. Unlike thermal NO production, where the temperature dependence of the rate of production of NO is largely due to the high activation energy of the reaction, the activation of the $\mathrm{CO}$ oxidation by $\mathrm{OH}$ is essentially zero and the temperature dependence is due to the strong temperature dependence of the [OH]. Thus, in late firing, the expanding combustion gases are rapidly cooling causing a corresponding rapid reduction in $[\mathrm{OH}]$ and thus a freezing of $\mathrm{CO}[28]$. Techniques for isolating and measuring $\mathrm{CO}$ from combustion gas are being developed for ${ }^{14} \mathrm{C}$ AMS. Combustion models indicate that wet $\mathrm{EtOH}(70 \%$ water) should also work as a HCCI fuel [29], with the added advantage that [OH] are likely to be higher and help complete combustion.

Figure 4 shows numerical model predictions of the reaction of DEE and EtOH in the HCCI combustion chamber. By adjusting the inlet temperature, we have caused the CA50 to occur later and later in the cycle. In all cases, the DEE begins to react before EtOH. As CA50 occurs later, we see more reaction of DEE relative to EtOH, which is consistent with the measurements in Fig. 2. We also see less reaction of both fuels, which is consistent with the measurements in Fig. 3 that show less $\mathrm{CO}_{2}$. 
The modeling results in Figure 5 show that DEE continues to react more so than EtOH, especially at late CA50 where reaction rates are decreasing. Recalling that it is $\mathrm{EtOH}$ that contains ${ }^{14} \mathrm{C}$, the retardation of EtOH reaction demonstrated in Fig. 5 supports the finding, seen in Fig. 2, that exhaust $\mathrm{CO}_{2}$ has a smaller mole fraction ${ }^{14} \mathrm{C}$ at late $\mathrm{CA} 50$.

In spite of the fact the DEE is clearly more reactive than EtOH, it is not by as much as we imagined. Experiments on $100 \% \mathrm{EtOH}$ and mixtures of $25 \% \mathrm{DEE}$ in $\mathrm{EtOH}$ at the same CA50 (6 degrees ATDC) had inlet temperatures of $148^{\circ} \mathrm{C}$ and $143^{\circ} \mathrm{C}$, respectively. For similar reasons, the spread in heat release and hence the reduction in pressure rise caused by the addition of DEE to EtOH is not significant in comparison with similar experiments done with DME and methane blends [23]. All of this suggests that a high efficiency, low pollution HCCI engine can run equally well on EtOH or mixtures of DEE in EtOH. Both EtOH and DEE are excellent fuels for HCCI. Both are readily obtained from biological sources and produce low NOx and low PM emissions. The data points to more complex mixtures being more amenable to an elongation of energy release.

\section{Conclusion}

Despite the rapid combustion typically experienced in HCCI, components in fuel mixtures do not ignite in unison or burn equally. In our experiments and modeling of blends of DEE and EtOH, the DEE led combustion and proceeded further toward completion $\left(\mathrm{CO}_{2}\right)$. DEE and EtOH are sufficiently similar that we did not observe a large elongation of energy release that would be desirable.

The numerical model and ${ }^{14} \mathrm{C}$ tracing data agreed within the limitations of the single zone model. Both approaches lacked information on incompletely combusted intermediates (CO, uncombusted fuel, acetaldehyde, etc.) plentiful in HCCI emissions.

We have shown that in HCCI combustion of a mixture of DEE in EtOH, the DEE is more reactive than the EtOH. This finding was made using ${ }^{14} \mathrm{C}$ isotope tracing. This finding suggests that, in general, HCCI combustion of fuel blends may have preferential combustion of some of the blend components.

The numerical model of HCCI combustion of DEE and EtOH mixtures supports the isotopic findings. 


\section{Acknowledgements}

This project is funded by the Department of Energy Office of FreedomCAR and Vehicle Technologies (Steve Goguen and Gurpreet Singh, Program Managers) the DOE University HCCI Program, and LLNL Laboratory Directed Research and Development grant 01-ERI-007. This work was performed in part under the auspices of the U.S. Department of Energy by University of California Lawrence Livermore National Laboratory under Contract No. W-7405-Eng-48. 


\section{References}

[1] F. Zhao, Homogeneous Charge Compression Ignition (HCCI) Engines: Key Research and Development Issues. SAE International, USA, 2003.

[2] R. Stone, Introduction to Internal Combustion Engines ( $3^{\text {rd }}$ Edition). SAE International, USA, 1999.

[3] J. Hiltner (Hiltner Combustion Systems) and S. Fiveland (Caterpillar). Personal Communication, June 2003.

[4] P. Flynn, G. Hunter, A. zur Luye, O. Akinyemi, R. Durrett, G. Moore, J. Mudd, G. Muntean, J. Wagner, J. Wright. “Premixed Charge Compression Ignition Engine with Optimal Combustion Control.” US Patent 6,286,482 B1. 2001.

[5] P. Flynn, G. Hunter, A. zur Luye, O. Akinyemi, R. Durrett, G. Moore, G. Muntean, L. Peters, P. Pierz, J. Wagner, J. Wright, J. Yeager. "Premixed Charge Compression Ignition Engine with Optimal Combustion Control." US Patent 6,276,334 B1. 2001.

[6] A. zur Loye, O. Akinyemi, R. Durrett, P. Flynn, G. Hunter, G. Moore, J. Mudd, G. Muntean, J. Wagner, J. Wright. "Premixed Charge Compression Ignition Engine with Optimal Combustion Control.” US Patent 6,230,683 B1. 2001.

[7] J. Torres, "Combustion of Natural Gas Augmented with Dimethyl Ether, Performed in a Homogeneous Charge Compression Ignited Engine.” MS Thesis, UC Berkeley, 1999.

[8] R.H. Stanglmaier, T.W. Ryan III, and J.S. Souder, "HCCI Operation of a Dual-Fuel Natural Gas Engine for Improved Fuel Efficiency and Ultra-Low NOx Emissions at Low to Moderate Engine Loads." SAE Technical Paper 2001-01-1897, 2001

[9] M. Christensen, B. Johansson, and P. Einewall, "Homogeneous Charge Compression Ignition Using Isooctane, Ethanol and Natural Gas - A Comparison with Spark Ignited Operation." SAE Paper No. 972874.

[10] J.S. Vogel, K.W. Turteltaub, R. Finkel, and D.E. Nelson, “Accelerator Mass Spectrometry - Isotope Quantification at Attomole Sensitivity," Anal. Chem., v67, 1995, pp.A353-A359.

[11] B.A. Buchholz, A.S. Cheng, R.W. Dibble, C.J. Mueller, and G.C. Martin, "Isotopic Tracing of Fuel Component Carbon in the Emissions From Diesel Engines" SAE Technical Paper 2002-01-1942, 2002.

[121] A.S. Cheng, R.W. Dibble, and B.A. Buchholz, "The Effect of Oxygenates on Diesel Engine Particulate Matter" SAE Technical Paper 2002-01-1705, 2002.

[13] B.A. Buchholz, A.S. Cheng, and R.W. Dibble, "Isotopic Tracing of Bio-Derived Carbon from Ethanol-in-Diesel Blends in the Emissions of a Diesel Engine" SAE Technical Paper 2002-01-1704, 2002.

[14] A.S. Cheng, B.A. Buchholz, and R.W. Dibble, "Isotopic Tracing of Fuel Carbon in the Emissions of a Compression-Ignition Engine Fueled With Biodiesel Blends" SAE Technical Paper 2003-01-2282, 2003. 
[15] B.A. Buchholz, R.W. Dibble, D. Rich, and A.S. Cheng, "Quantifying the contribution of lubrication oil carbon to particulate emissions from a diesel engine" SAE Technical Paper 2003-01-1987, 2003.

[16] J.S. Vogel, J.R. Southon, and D.E. Nelson, "Catalyst and Binder Effects in the Use of Filamentous Graphite for AMS” Nucl. Instrum. Methods Phys. Res. Sect. B v29, 1987, pp.50-56.

[17] M.L. Roberts, G.S. Bench, T.A. Brown, M.W. Caffee, R.C. Finkel, S.P.H.T. Freeman, L.J. Hainsworth, M. Kashgarian, J.E. McAninch, I.D. Proctor, J.R. Southon, and J.S. Vogel, “The LLNL AMS Facility” Nucl. Instru. Meth. B, v123, 1997, pp.57-61.

[18] H.J. Curran, W.J. Pitz, C.K. Westbrook, P. Dagaut, J.-C. Boettner, and M. Cathonnet, "A Wide Ranging Study of Dimethyl Ether Oxidation," International Journal of Chemical Kinetics, 1998. 30(3): p. 229-241.

[19] H.J. Curran, "Reaction Mechanism for Oxidation of Diethyl Ether," to be submitted. 2003.

[20] N.M. Marinov, "A Detailed Chemical Kinetic Model for High Temperature Ethanol Oxidation," International Journal of Chemical Kinetics 31:183-220, 1999.

[21] D. Flowers, S. Aceves, J.R. Smith, J. Torres, J. Girard, and R. Dibble, "HCCI in a CFR Engine: Experiments and Detailed Kinetic Modeling," SAE Paper 2000-01-0328. 2000.

[22] D.L. Flowers, S.M. Aceves, C.K. Westbrook, J.R. Smith, and R.W. Dibble, "Detailed Chemical Kinetic Simulation of Natural Gas HCCI Combustion: Gas Composition Effects and Investigation of Control Strategies," ASME J. of Eng. Gas Turb. Power, 2001. 123: p. 433-439.

[23] D.L. Flowers, "Combustion in Homogeneous Charge Compression Ignition Engines: Experiments and Detailed Chemical Kinetic Modeling," PhD Dissertation, UC Davis, 2001.

[24] G. Woschni, "Universally Applicable Equation for the Instantaneous Heat Transfer Coefficient in the Internal Combustion Engine," SAE Paper 670931, SAE Trans., vol. 76, 1967.

[25] G. Woschni and J. Fieger, "Experimental Investigation of the Heat Transfer at Normal and Knocking Combustion in Spark Ignition Engines," MTZ, vol. 43, 1982.

[26] K. Sihling and G. Woschni, "Experimental Investigation of the Instantaneous Heat Transfer in the Cylinder of a High Speed Diesel Engine," SAE paper 790833, 1979.

[27] J.B. Heywood, Internal Combustion Engine Fundamentals. McGraw-Hill. New York, NY, USA. 1988.

[28] J. Warnatz, U. Mass, and R.W. Dibble. Combustion. (3 $3^{\text {rd }}$ Edition). Springer Press, Germany, 2001.

[29] M. Christensen and B. Johansson, "Homogeneous Charge Compression Ignition with Water Injection," SAE Technical Paper 1999-01-0182. 1999. 
Tables

\begin{tabular}{|l|l|}
\hline Configuration & Single Cylinder \\
\hline Valves & 4 (2 int., 2 exh.) \\
\hline Compression Ratio & 16.25 \\
\hline Displacement & $2.44 \mathrm{~L}$ \\
\hline Camshaft Lobe Lift (Exhaust) & $8.796 \mathrm{~mm}$ \\
\hline Camshaft Lobe Lift (Intake) & $8.113 \mathrm{~mm}$ \\
\hline
\end{tabular}

Table I: Engine Specification for CAT3401

\begin{tabular}{|c|c|c|c|c|c|}
\hline \multirow{2}{*}{ Fuel } & Formula & Molar Mass (g/mol) & LHV $(\mathbf{M J} / \mathbf{k g})$ & $\mathbf{a}$ (stoich.) & $\mathbf{1 4 C / C}$ ratio \\
\hline $\mathrm{EtOH}$ & $\mathrm{CH} 2 \mathrm{CH} 3 \mathrm{OH}$ & 46 & 26.803 & 9 & $1.3 \mathrm{E}-12$ \\
\hline $\mathrm{DEE}$ & $\mathrm{CH} 2 \mathrm{CH} 3 \mathrm{OCH} 3 \mathrm{CH} 2$ & 74 & 33.900 & 11.2 & $<1 \mathrm{E}-15$ \\
\hline
\end{tabular}

Table II: Fuel Properties of EtOH and DEE 


\section{Figures}

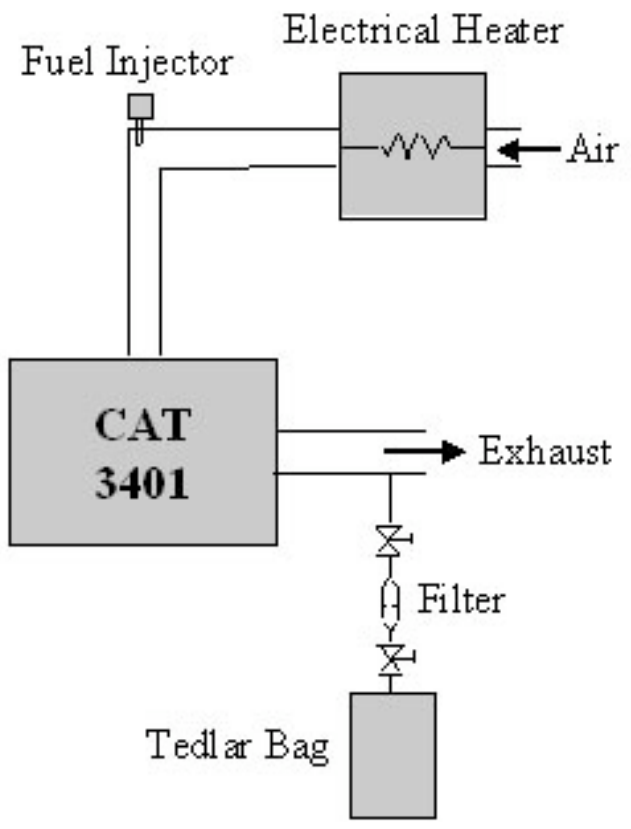

Fig. 1. Experimental set-up for exhaust collection from the single cylinder CAT3401 engine

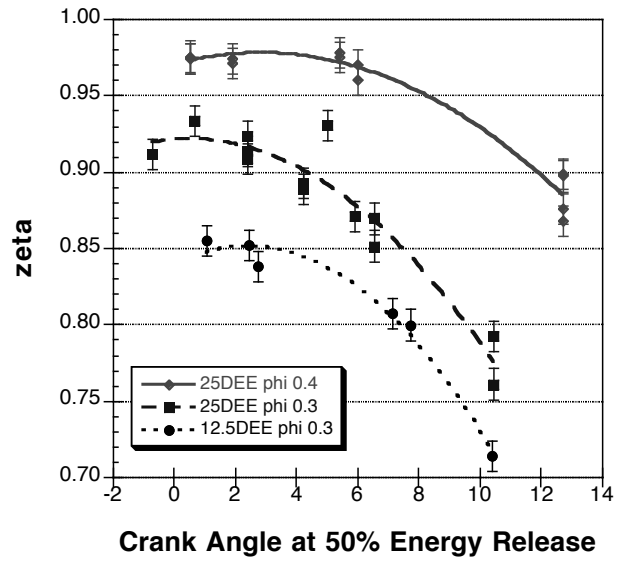

Fig. 2. Zeta, the mass fraction $\mathrm{EtOH}$ in $\mathrm{CO}_{2}$ normalized to fuel, for three fuels mixtures. Error bars assume $1 \%$ uncertainty in fuel concentration. The uncertainty in the fuel shifts the whole series up or down (the accuracy).

However, the precision is unchanged. 


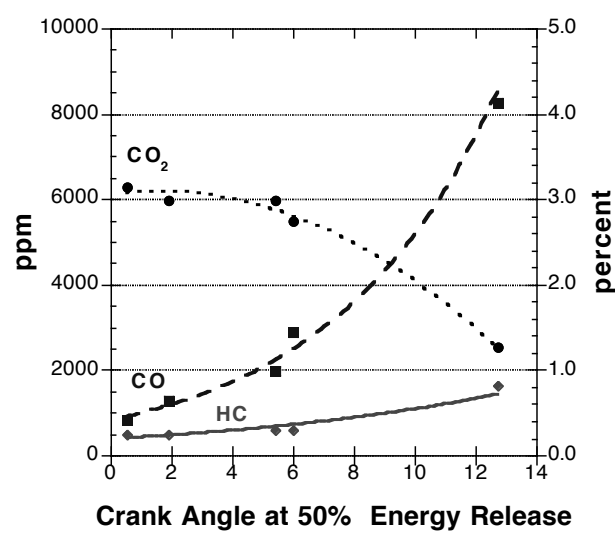

Fig. 3. Gas analyzer data for $25 \% \mathrm{DEE}$ in $\mathrm{EtOH}$ at _- $0.4 ; \mathrm{CO}_{2}$ (in percent), decreases as $\mathrm{CA} 50$ is delayed, while $\mathrm{CO}$ and $\mathrm{HC}$ (in ppm) increases.

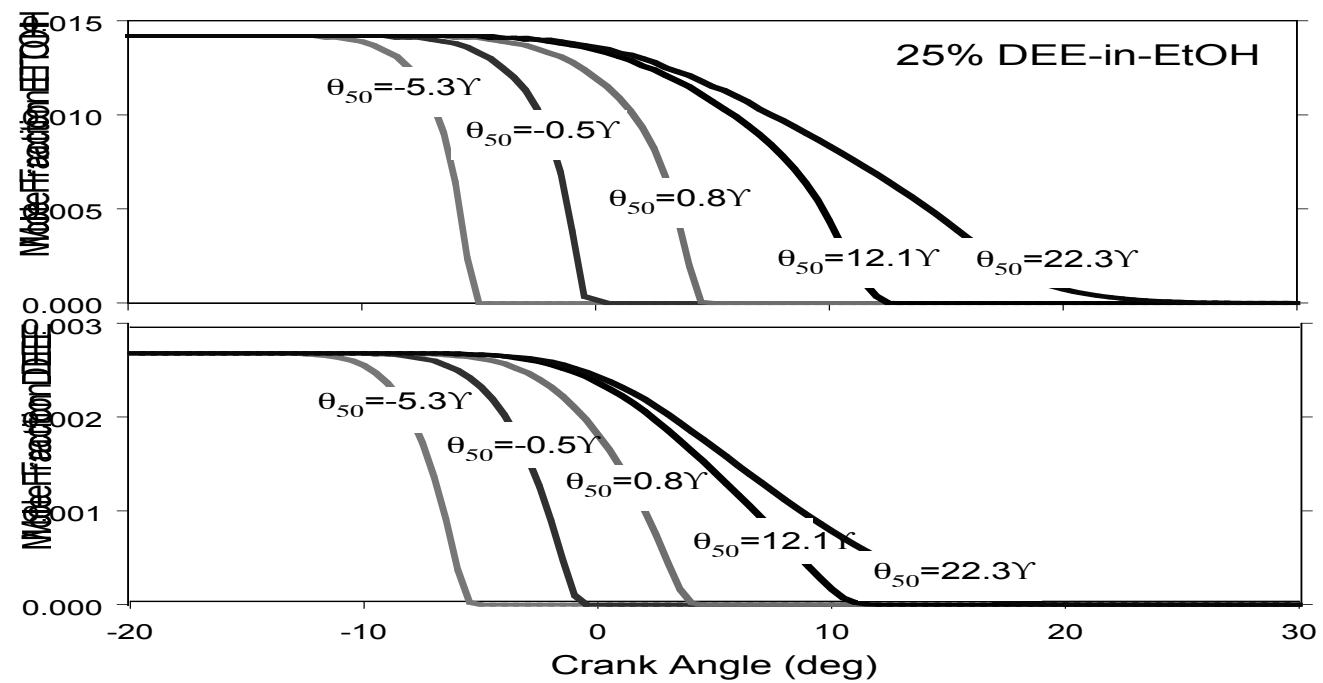

Fig. 4. Simulation results of mole fraction history of the fuel components for various combustion timings based on $50 \%$ burn location 


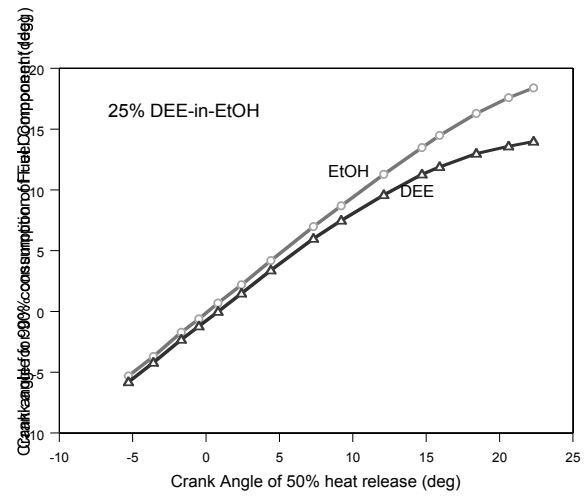

Fig. 5. Simulation results comparing timing of consumption relative to the overall combustion timing based on crank angle for $50 \%$ of the heat release. The fuel consumption timing used is the time at which $90 \%$ of the fuel has been consumed 